\title{
Dual effects of a second-order conditioned stimulus: Excitation and inhibition
}

DENNIS HERENDEEN, University of California, Santa Barbara, Calif. 93106 and D. CHRIS ANDERSON, University of Notre Dame, Notre Dame. Ind. 46556

On alternate days during Sidman avoidance training, four groups of four Ss each were conditioned in a separate chamber. Group 1 received 10 forward first-order $\left(C S_{1}-U S\right)$ and 20 forward second-order $\left(C S_{2}-C S_{1}\right)$ conditioning trials until 100 of the former and 200 of the latter were completed. For Group 2 second-order trials involved a random contingency. Only the $C S_{1}$ was presented Group 3 on the first 180 of the 200 second-order trials. Group 4 was like Group 3 except that the last $20 \mathrm{CS}_{2}-C S_{1}$ trials involved a random contingency. During extinction of the avoidance response onset of $C S_{1}$ occasioned accelerated response rates for all groups. $C S_{1}$ offset produced below-baseline response depression. The $\mathrm{CS}_{2}$ accelerated responding for Group 3, depressed performance for Group 1, and left basically unchanged Groups 2 and 4.

The classical paradigm for second-order conditioning (cf., Pavlov, 1927) involves pairing a new neutral stimulus $\left(\mathrm{CS}_{2}\right)$ with an already-established first-order conditioned stimulus $\left(\mathrm{CS}_{1}\right)$. While, until recently, evidence for the efficacy of this procedure has been discouraging, recent findings (Anderson, Plant, Johnson, \& Vandever, 1967; McAllister \& McAllister, 1964) indicated that the effects of a $\mathrm{CS}_{2}$ upon indicant behavior paralleled those of a $\mathrm{CS}_{1}$. It thus was surprising to find a report that a $\mathbf{C S}_{2}$ produced opposite effects to the $\mathrm{CS}_{1}$ with which it had been paired (Rescorla \& LoLordo, 1965). Dogs, trained to stable performance in a shuttle box on a Sidman avoidance schedule, occasionally were presented a $C S_{1}$ or a $\mathrm{CS}_{2}$. While the $\mathrm{CS}_{1}$ augmented response rate, the $\mathrm{CS}_{2}$ produced attenuation.

One factor which might account for these results was the number of conditioning trials employed relative to those in other studies of mediated classical conditioning (i.e., 90 of each order vs 20-30 first- and 25-40 second-order elsewhere). Noting that on second-order trials the $C S_{2}$ invariably signals that the $C S_{1}$ will not be followed by the US, extensive $\mathrm{CS}_{2}-\mathrm{CS}_{1}$ pairings may result in a discrimination between the occurrence and non-occurrence of shock. Thus, although the $\mathrm{CS}_{2}$ may acquire some of the properties of the $\mathrm{CS}_{1}$ due to its contiguity with $\mathrm{CS}_{1}$-produced shock expectation on early conditioning trials, more extensive conditioning may render the $\mathrm{CS}_{2}$ as a signal for omission of shock in the presence of the $C S_{1}$.

\section{METHOD}

Sixteen male, naive, albino rats, 90-100 days of age were used. The apparatuses were a two-way shuttle box, described elsewhere (Anderson, Schwendiman, \& Dunford, 1966), and a highlyconfined cylindrical conditioning chamber, also described elsewhere (Anderson et al, 1967).

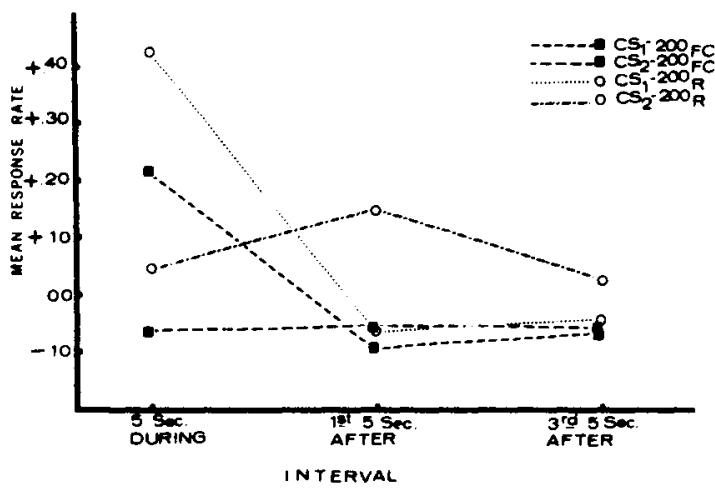

Fig. 1. Mean response rate to and following $\mathrm{CS}_{1}$ and $\mathrm{CS}_{2}$ presentation for the extended-forward and random conditioned groups.
All rats were given daily 'idman avoidance training ( $R-S$ interval of $25 \mathrm{sec}$ ) until some semblance of response stability was observed (after six 1-h sessions). Then, on alternate days four groups of four Ss each, equated for R-S ratios on the sixth day of avoidance training, were conditioned. One group $\left(200_{\mathrm{FC}}\right)$ was given 100 $C S_{1}-U S$ and $200 \mathrm{CS}_{2}-\mathrm{CS}_{1}$ trials, 10 of the former and 20 of the latter of which were presented every other day over a 20-day period in the cylindrical chamber. With the exception that the first five first-order trials of the first conditioning day were consecutively administered, the order of first- and second-order pairings was random. The $\mathrm{CS}_{1}$ was a 5 -sec buzzer which overlapped and co-terminated with a $2-\mathrm{sec}, 135 \mathrm{~V}$ ac shock US (in series with $22 \mathrm{~K}$ ohms) on first-order trials. The $\mathrm{CS}_{2}$ was a 10-sec intermittent $7-1 / 2-W$ light which overlapped and co-terminated with the $\mathrm{CS}_{1}$ on second-order trials. Following Rescorla (1967), the second group $\left(200_{R}\right)$ was a control for second-order pairings. The $\mathrm{CS}_{2}$ and $\mathrm{CS}_{1}$ relationship was entirely random for the 200 second-order presentations.

The third group $\left(20_{\mathrm{FC}}\right)$ was identical to the first except that the $\mathrm{CS}_{2}$ was omitted on the first 180 second-order trials. The last 20 trials involved the regular forward $\mathrm{CS}_{2}-\mathrm{CS}_{1}$ contingency. The only difference for the fourth group $\left(20_{R}\right)$ was that the last 20 second-order pairings involved the random contingency.

Unfortunately, by the end of conditioning, avoidance behavior was markedly impaired. Thus, $24 \mathrm{~h}$ following conditioning, six consecutive sessions of Sidman training, uninterrupted by conditioning on alternate days, were given. This partially re-established performance levels, although not completely.

Testing consisted of continuation of Sidman training for the first $30 \mathrm{~min}$ of the 1-h session. Shock then was turned off and, while $S$ continued to respond, both the $\mathrm{CS}_{1}$ and $\mathrm{CS}_{2}$ randomly were presented ( $5 \mathrm{sec}$ each) for a total of two presentations each. This procedure was repeated for five consecutive days for a total of $10 \bar{C} S_{1}$ and $10 C S_{2}$ presentations.

\section{RESULTS}

Number of responses for the 5-sec periods preceding both $\mathrm{CS}_{1}$ and $\mathrm{CS}_{2}$, during presentations of each, and during the three consecutive $S$-sec periods following their termination were obtained. Since pre-CS responding did not differ across groups or CS conditions ( Fs $<1$ ), they were combined and averaged to form a common baseline to compare responses to anc following respective CS presentations. Figures 1 and 2 represent the results of these comparisons.

Figure 1 involved the extended-conditioning experimental $\left(200_{\mathrm{FC}}\right)$ and control $\left(200_{\mathrm{R}}\right)$ groups during and following $\mathrm{CS}_{1}$ and $\mathrm{CS}_{2}$ presentations. The $C S_{1}$ was the occasion for accelerated performances for both groups $\left(C S_{1}-200_{F C}\right.$ and $\left.C S_{1}-200_{R}\right)$. However, a precipitous drop to below baseline level occurred for both immediately following termination of the $\mathrm{CS}_{1}$, with only

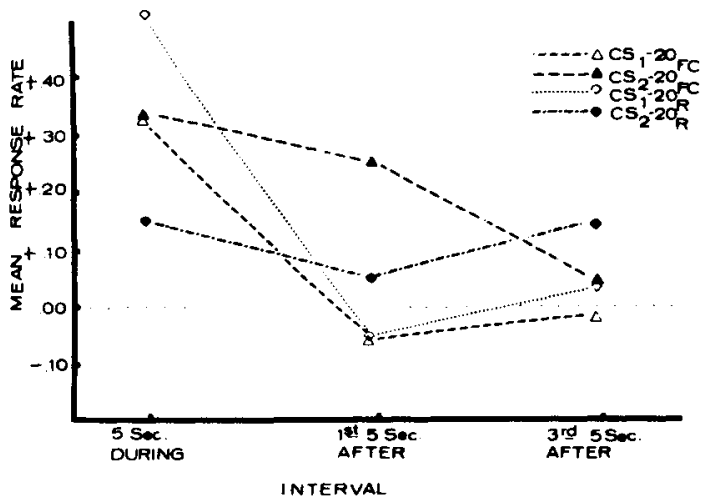

Fig. 2. Mean response rate to and following $\mathrm{CS}_{1}$ and $\mathrm{CS}_{2}$ presentation for the reduced-forward and random conditioned groups. 
minimal recovery after $15 \mathrm{sec}$. More importantly, the $\mathrm{CS}_{2}$ slightly accolerated response rate in controls $\left(\mathrm{CS}_{2}-200_{R}\right)$ but attenuated performance for experimentals $\left(\mathrm{CS}_{2}-200_{\mathrm{FC}}\right)$. The Fs approached but did not quite achieve significance for respective comparisons at each temporal interval for the $\mathrm{CS}_{2}$ data.

Groups $20_{\mathrm{FC}}$ and $20_{\mathrm{R}}$ are represented in Fig. 2. The $C S_{1}$ again produced an augmented response rate (relative to baseline) followed by a post-CS depression in performance. In contrast with Groups $200_{\mathrm{FC}}$ and $200_{\mathrm{R}}$, the $\mathrm{CS}_{2}$ produced a marked augmentation of response rate for the experimental group $\left(\mathrm{CS}_{2}-20_{\mathrm{FC}}\right)$ during and following its occurrence.

Again, while the trend was strongly toward statistical significance, it was not quite achieved in all instances. As in the preceding analyses for the extended-conditioning groups, there was a significant $F$ representing the drop in performance between $C S_{1}$ presentation and offset. Moreover, a comparison between the $\mathrm{CS}_{2}$-produced performance changes in the extended- $\left(\mathrm{CS}_{2}-200_{\mathrm{FC}}\right)$ vs the reduced-forward conditioned groups $\left(\mathrm{CS}_{2}-2 \mathrm{~F}_{\mathrm{FC}}\right)$ resulted in a significant $F(p<.05)$. So also was the $F$ based on a comparison of the extended-forward conditioned group vs the combined $\mathrm{CS}_{2}$ performances of the two controls $(p<.05)$.

$$
\text { DISCUSSION }
$$

A $\mathrm{CS}_{2}$, established after a few conditioning trials, apparently can act like a fear-evoking $\mathrm{CS}_{1}$; a finding consonant ivith, for example, Anderson et al (1967). Moreover, when based on extensive training, the $\mathrm{CS}_{2}$ apparently changed "valence" from a fear-evoking stimulus to something akin to relaxation or relief. As a signal for no shock, it served to depress fear-motivated test performance, thus supporting Rescorla \& LoLordo (1965). One possible reason for the lack of even more pronounced suppression to the $\mathrm{CS}_{3}$ for the extended-forward conditioned group was the quite low baseline response level. This imposed a sort of reversed ceiling effect thus precluding probable complete detection of a more completely depressed performance. None the less, the direction was with the hypothesis, and was consistent across animals, temporal intervals, and with our preliminary work (Anderson \& Herendeen, 1967).

The significant drop for all groups following $\mathrm{CS}_{1}$ suggested, because its offset consistently signalled a shock-free period during conditioning, that it assumed the same inhibitory function as did the $\mathrm{CS}_{2}$ for the $\mathrm{CS}_{2}-200_{\mathrm{FC}}$ condition.

\section{REFERENCES}

ANDERSON, D. C., PlanT, C., JOHNSON, D., \& VANDEVER, J. Second-order aversive classical conditioning. Canadian Journal of Psychology, 1967, 21, 120-131.

ANDERSON, D. C., HERENDEEN, D. Dual function of a higher-order conditioned stimulus as revealed in a Sidman avoidance test situation. Paper presented at the Psychonomic Society meetings, Chicago, September, 1967.

ANDERSON, D. C., SCHWENDIMAN, G., \& DUNFORD, G. Retention of an incompletely learned avoidance response: Some problems with replication. Psychonomic Science, 1966, 6, 23-24.

McALLISTER, D. E., \& McALLISTER, W. R. Second-order conditioning of fear. Psychonomic Science, 1964, 1, 383-384.

PAVLOV, I. P. Conditioned reflexes Translated by G. V. Anrep. London: Oxford University Press, 1927.

RESCORLA, R. A., \& LoLORDO, V. M. Inhibition of avoidance behavior. Joumal of Comparative \& Physiological Psychology, 1965, 59, 406412.

RESCORLA, R. A. Pavlovian conditioning and its proper control procedures. Psychological Review, 1967, 74, 71-80. 